\title{
The Use of Grey Systems Theory to Analyze the Water Supply Systems Safety
}

\section{Dawid Szpak $^{1}$ (D) Barbara Tchórzewska-Cieślak ${ }^{1}$ (D)}

Received: 12 February 2019 / Accepted: 18 August 2019 /

Published online: 31 August 2019

(C) The Author(s) 2019

\begin{abstract}
New requirements for water supply companies enforce the implementation of risk analysis and assessment methods on many levels of their operation. The approach recommended by the World Health Organization and the European Commission based on threats prevention from intake to water consumers is becoming more and more popular. The paper presents a threeparameter risk matrix that can be used for the implementation of Water Safety Plans. It was also proposed to use the grey systems theory, which allowed for the extension of the risk matrix analysis method. The grey systems theory makes it possible to make decisions in the lack of complete information. This may be of particular importance in the small water supply systems safety analysis where monitoring and management capabilities are limited. The developed method may constitute basis for procedures to ensure the water supply safety for water supply system operators, burdened with more and more obligations resulting from both national and European regulations.
\end{abstract}

Keywords Water supply system $\cdot$ Safety

\section{Introduction}

The affiliation of the water supply system (WSS) to the critical infrastructure requires from water supply companies to ensure the continuity of functioning and to quickly restore the state of efficiency in case of an undesirable event. Efficiency is understood as the proper operation (functioning) of a device or object. There are three groups of factors that constitute the cause of undesirable events in the WSS: technical, human and environmental. One can primarily speak about the threat to health and life of residents when the water supplied to consumers does not meet the quality requirements set for water intended for consumption. In case of lack or

Dawid Szpak

dsz@prz.edu.pl

1 Department of Water Supply and Sewage Systems, Faculty of Civil and Environmental Engineering and Architecture, Rzeszów University of Technology, Powstańców Warszawy 6, 35-959 Rzeszów, Poland 
limitation of water supply, the health and life of water consumers is not directly endangered, however there is some sanitary hazard associated with the lack of possibility of maintaining proper personal hygiene.

In environmental engineering (as in most engineering applications) the basic risk definition applies, which presents risk as a product of the probability of undesirable events occurrence and losses resulting from it. Although risk has been subject to analysis and evaluation in the eighties of the twentieth century (Kaplan and Garrick 1981), the concept of risk has not been clearly defined yet and risk is assessed in many ways (Boryczko and Tchórzewska-Cieślak 2013; Foster and McDonald 2000). Risk as a measure of loss of safety has become the paradigm in technical sciences. Safety, however, is understood as the system's ability to protect its superior functional properties against internal and external threats. For the WSS, it is to protect consumers against consuming water of inadequate quality or lack of water supply, at present and in the future, as a result of escalation of undesirable events (domino effect). Studies related to the safety of the WSS focus mainly on the quality of tap water and its impact on the health of consumers. The paper (Rak and Pietrucha-Urbanik 2008) proposes an assessment of health risk based on a risk matrix. The method of determining the microbiological risk was proposed in the work (Smeets et al. 2010). A considerable number of publications concern trihalomethanes (THMs) present in water. The negative impact of THMs present in water on the risk of miscarriage was demonstrated (Dodds et al. 2004). The way of communication between the water supply company and consumers after the occurrence of contamination was analysed in work (Byleveld et al. 2008). The issue of water deficits was raised, among others, in work (Perrier et al. 2014) and (Tchorzewska-Cieslak et al. 2011). In some publications, an attempt was also made to assess the safety of WSS, based on computer software, in both qualitative (Kistemann et al. 2001) and quantitative (Pietrucha-Urbanik and Studzinski 2017, Piegdoń et al. 2017) aspects. This work focuses on the quantitative aspect of water supplied to consumers. In the perspective of a few years, all European water companies will be obliged to carry out a risk analysis covering all stages of water supply from the intake to the consumer under the Water Safety Plans (WSP) which have been developed by the World Health Organization (WHO). Proposal for a Directive of the European Parliament and the Council of 1 February 2018 on the quality of water intended for human consumption informs that "(...) a risk-based approach should be progressively implemented by all water suppliers, including small entities". Among other things, this provision caused that water supply companies increased their interest in methods of risk analysis and management as well as the possibilities resulting from their implementation.

Many European countries, including Germany, introduced a risk management model, from the intake to the consumer, for daily operation, which improved the quality of operation of local water supply companies and reduced the number of undesirable events. A number of authors draw attention to the benefits of the Water Safety Plans implementation (Gunnarsdottir et al. 2012; Maelzer et al. 2010]. In some countries, including Poland, there is currently no obligation to implement the WSP, therefore the vast majority of water supply companies have not implemented the WSP in their WSS, probably waiting for appropriate legal conditions and belittling possibilities offered by the WSP implementation. The World Health Organization recommends using a semi-quantitative method, a two-parameter risk matrix, based on severity and probability parameter. As an alternative, the WHO proposes a simplified risk assessment based on the opinion of the expert team. Each event should be assessed by experts as 'significant', 'unspecified' or 'insignificant'. It is recommended to validate safety measures later. This approach to risk analysis does not allow for a detailed assessment of the functioning 
of the WSS. The main argument here is, first of all, related to the fact that in the matrix method the individual parameters describing an undesirable event may have different meanings in a given situation, e.g. other for a water intake and other for a water supply network. In addition, all the input parameters (probability, losses) are synonymous and have the same impact on the risk value, which is also difficult to agree with. Therefore, searching for new or improving current risk analysis methods is justified and should mainly concern the development of risk matrices dedicated to individual subsystems and taking into account their specificity, i.e. separately for the water intake, for the water treatment plant, for the water pumping stations, for the water supply tanks and, finally, for the water supply network. One should also attempt to eliminate the subjectivity of the analysis, because the matrix method is an expert method and the adoption of appropriate values of the input parameters is often ambiguous and based on intuition. It is also important to determine the parameters that have the greatest impact on the loss of safety.

The main objective of the work is to analyse the safety of the WSS based on the author's risk matrix using the theory of grey systems, has been widely used in many fields (Yin 2013). The use of grey systems theory reduces the probability of error during risk analysis and assessment, e.g. for WSP. The analysis uses membership functions, which makes it more reliable, because a partial membership of the object is possible which allows the uncertainty factor to be taken into account. The analysis covers grey systems, i.e. those where the database is incomplete or uncertain. Parameters are described by using linguistic values (low, medium, high), which is more intuitive for the person who carries out the analysis. In order to determine the degree of relation, the value of the factor for the input parameters is determined, i.e. P, I and U, which allows to determine which ones have the greatest impact on the risk value. The proposed method complements the statistical and fuzzy approach and enables analysis of the system's functioning by means of relationship analysis. It can be extended depending on the specifics of a given water supply system and the required level of detail of the analysis. This paper addresses the current standards for the safety of water intended for human consumption, developed by the World Health Organization (WHO) (WHO 2009) and is a new approach to risk analysis in water supply systems.

\section{Research Methodology}

\subsection{Risk Matrix}

The paper proposes the use of the author's three-parameter risk matrix, which can be used for risk analysis in WSP:

$$
r=P \cdot I \cdot U
$$

where:

$P$ point weight related to the percentage share of a given type of failure,

$I$ point weight related to the failure rate of the water supply network (according to the formula 2),

$U$ point weight related to a nuisance to consumers. 
The developed risk matrix is dedicated to the water supply network, which is the most susceptible to failures subsystem included in the WSS. Failures can be caused by random events, human interference or a combination of operation of time, excessive stress and adverse environmental conditions. The failure rate index is determined from the formula (Kwietniewski and Rak 2010):

$$
\lambda=\frac{\mathrm{n}(\Delta \mathrm{t})}{\mathrm{L} \cdot \Delta \mathrm{t}}
$$

where:

$n(\Delta t)$ number of failures in the time interval $\Delta t$,

$L \quad$ length of examined pipes in the time interval $\Delta \mathrm{t}[\mathrm{km}]$,

$\Delta t \quad$ the considered time interval [years].

In quantitative matrix methods for all risk parameters appropriate point weights are assigned (in the adopted scale). The risk assessment is a comparison of the determined values with the risk acceptance criteria, which is the basis for the safety analysis. The individual parameters are described by an integer based on the following point scale:

- low, $\mathrm{L}=1$,

- medium, $\mathrm{M}=2$,

- high, $\mathrm{H}=3$.

The entry criteria for the individual parameters are adopted on the basis of the information contained in Table 1. The limit values of the failure rate indexes are not regulated by law, therefore the paper refers to the values providrd, among others, in work (Kwietniewski and Rak 2010). It was proposed to introduce three intervals for the time of water supply withholding:

- $\leq 3 \mathrm{~h}$-there are no significant impediments to the functioning of consumers, it can be assumed that $3 \mathrm{~h}$ is a break between meals,

- $\quad(3 \mathrm{~h}-12 \mathrm{~h}>-$ there is a need to buy bottled water for consumption and to prepare meals, or use of water carts (about $0.0075 \mathrm{~m}^{3} /(\mathrm{M} \cdot \mathrm{d})$ ),

- $>12 \mathrm{~h}$ - there is a need to purchase bottled water for the purposes of maintaining personal hygiene and for economic needs (washing the dishes, keeping the apartments clean) or using the water carts (about $0.015 \mathrm{~m}^{3} /(\mathrm{M} \cdot \mathrm{d})$ ).

Table 1 Criteria and point weights for parameters $\mathrm{P}$, I and $\mathrm{U}$

\begin{tabular}{|c|c|c|c|}
\hline $\begin{array}{l}\text { Percentage of a given } \\
\text { type of failure }(\mathrm{P})\end{array}$ & $\begin{array}{l}\text { Water supply network } \\
\text { failure rate } \lambda(I)\end{array}$ & Nuisance (U) & Point weight \\
\hline$\leq 0.25$ & $\leq 0.5$ failure/(km·year) & $\begin{array}{l}\text { suspension of water supply } \\
\text { for a period of } \leq 3 \mathrm{~h}\end{array}$ & $\mathrm{~L}=1$ \\
\hline$(0.25-0.5>$ & $(0.5-1.0>$ failure $/(\mathrm{km} \cdot$ year $)$ & $\begin{array}{l}\text { suspension of water supply } \\
\text { for a period of }(3 h-12 h>\end{array}$ & $M=2$ \\
\hline$>0.5$ & $>1.0$ failure $/(\mathrm{km} \cdot \mathrm{year})$ & $\begin{array}{l}\text { suspension of water supply } \\
\text { for a period of }>12 \mathrm{~h}\end{array}$ & $\mathrm{H}=3$ \\
\hline
\end{tabular}




\subsection{Grey Systems Theory}

Despite the fact that matrix methods are increasingly used by water utilities for the needs of the WSP (which is consistent with the WHO recommendations), their assumptions are often criticized. The proposed matrix, however, is based on strictly defined numerical values, which reduces the subjectivity of the analysis (Table 1). The method focuses on the quantitative aspect of water supplied to consumers. Adequate quality of tap water supplied to consumers, which is monitored by both the water supply company and the local sanitary epidemiological station is also an important issue.

Due to the limitations of the conventional matrix method, it was proposed to modify it by the theory of grey systems described by J.L. Deng (1982). It can be used to analyse the operation of systems in which the database is incomplete or uncertain (socalled grey systems). In practice, it can be said that the whole world is a complex grey system, because many things cannot be predicted completely, they are uncertain (e.g. weather, natural disasters). White systems, about which everything is known and which can be described by the classic statistics, are rare. The theory of grey systems may be of particular importance in analysing the safety of water consumers supplied from small and medium-sized WSS with a limited database which often do not have WSP implemented. It enables making decisions in the absence of complete information. It is particularly important if the water supply company does not keep a register of undesirable events of a given type or a given event has not occurred so far (which obviously does not preclude its occurrence in the future).

To assess the input parameters $\mathrm{P}, \mathrm{I}$ and $\mathrm{U}$, the trapezoidal and triangular membership functions were used, due to the small number of data needed to define the function and the ability to modify function parameters during the analysis, as shown in Fig. 1. Choosing the appropriate membership function is a very important stage in the developed method of analysing undesirable events and has a significant impact on the results of the analysis. These parameters are evaluated using linguistic variables (low, medium, high). The boundaries of sets in this case are not clearly defined. There is a gradual transition from the lack of the membership to the full membership of a given element in the set. Since the use of the grey systems theory in failure mode and effects analysis raises the efficiency of analysis (Pillay and Wang 2003; Chang et al. 1999), it should be expected that its use in the matrix method will also allow to reduce the disadvantages of this method.

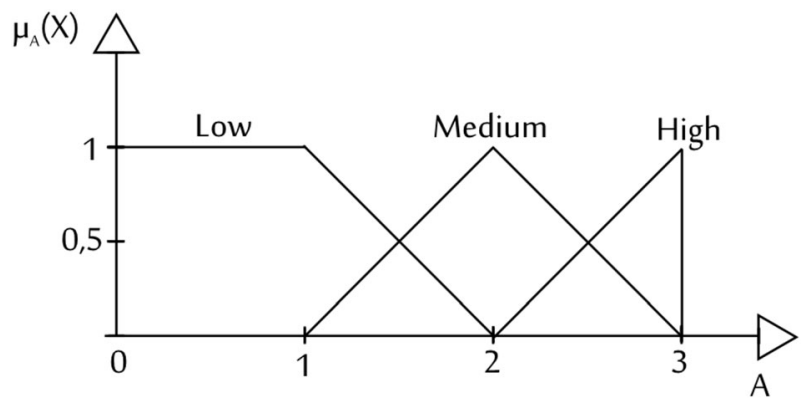

Fig. 1 Membership function of parameters $\mathrm{P}$, I and U 
After assigning to each parameter describing the undesirable events the corresponding linguistic variable, sharp values are determined, in accordance with the relationship proposed in the works (Chen and Klien 1997):

$$
\mathrm{K}(\mathrm{x})=\frac{\sum_{\mathrm{i}=0}^{\mathrm{n}}\left(\mathrm{b}_{\mathrm{i}}-\mathrm{c}\right)}{\sum_{\mathrm{i}=0}^{\mathrm{n}}\left(\mathrm{b}_{\mathrm{i}}-\mathrm{c}\right)-\sum_{\mathrm{i}=0}^{\mathrm{n}}\left(\mathrm{a}_{\mathrm{i}}-\mathrm{d}\right)}
$$

where:

$\mathrm{K}(\mathrm{x})$ defuzzified crisp number.

The values of $c$ (beginning of the range; $c=0$ ) and $d$ (end of the compartment; $d=3$ ) are constant for all the linguistic variables, the values $a_{0}$ and $b_{0}$ refer to the boundaries of each linguistic variable (the membership function is 0 ), while the values $a_{1}$ and $b_{1}$ are determined for the boundaries of individual variables, where the membership function is 1 .

A comparative series having $\mathrm{n}$ elements can be represented as $\mathrm{x}_{\mathrm{i}}^{\prime}=\left(\mathrm{x}_{\mathrm{i}}^{\prime}(1), \mathrm{x}_{\mathrm{i}}^{\prime}(2), \ldots, \mathrm{x}_{\mathrm{i}}^{\prime}(\mathrm{k})\right) \in \mathrm{X}$, where means $\mathrm{k}$-th indicator $\mathrm{x}_{\mathrm{i}}$. If all the series are comparable, they can be presented in the form of the following matrix:

$$
\mathrm{x}=\left[\begin{array}{l}
\mathrm{x}_{1} \\
\mathrm{x}_{2} \\
\cdots \\
\mathrm{x}_{\mathrm{n}}
\end{array}\right]=\left[\begin{array}{ccc}
\mathrm{x}_{1}(1) & \mathrm{x}_{1}(2) & \mathrm{x}_{1}(3) \\
\mathrm{x}_{2}(1) & \mathrm{x}_{2}(2) & \mathrm{x}_{2}(3) \\
\cdots & \cdots & \cdots \\
\mathrm{x}_{\mathrm{n}}(1) & \mathrm{x}_{3}(2) & \mathrm{x}_{3}(3)
\end{array}\right]
$$

A standard series of decision factors is generated by determining the optimal level of all the parameters affecting the risk value. From the point of view of water consumers, one should strive to achieve the lowest possible level of the individual parameters. The standard series can be presented in the form $\mathrm{x}_{0}=\left[\mathrm{x}_{0}(1), \mathrm{x}_{0}(2), \ldots, \mathrm{x}_{0}(\mathrm{k})\right]=[$ low, low, low $]$. This information, like the comparative series, is presented as a matrix (Pillay and Wang 2003).

Differences between the comparative series and the standard series are presented in the form of a matrix (Pillay and Wang 2003):

$$
\mathrm{D}_{0}=\left[\begin{array}{ccc}
\Delta_{01}(1) & \Delta_{01}(2) & \Delta_{01}(3) \\
\Delta_{02}(1) & \Delta_{02}(2) & \Delta_{02}(3) \\
\cdots & \cdots & \cdots \\
\Delta_{\mathrm{m}}(1) & \Delta_{\mathrm{m}}(2) & \Delta_{\mathrm{m}}(3)
\end{array}\right]
$$

where:

$$
\Delta_{0 \mathrm{j}}(\mathrm{k})=\left|\mathrm{x}_{0}(\mathrm{k})-\mathrm{x}_{\mathrm{i}}(\mathrm{k})\right|
$$

$\mathrm{x}_{0}(\mathrm{k}) \quad$ the standard series,

$\mathrm{xi}(\mathrm{k})$ the comparative series.

Grey relation coefficient is determined from the formula (Deng 1989):

$$
\gamma\left(\mathrm{x}_{0}(\mathrm{k}), \mathrm{x}_{\mathrm{i}}(\mathrm{k})\right)=\frac{\min _{\mathrm{i}} \min _{\mathrm{k}}\left|\mathrm{x}_{0}(\mathrm{k})-\mathrm{x}_{\mathrm{i}}(\mathrm{k})\right|+\zeta \max _{\mathrm{i}} \max _{\mathrm{k}}\left|\mathrm{x}_{0}(\mathrm{k})-\mathrm{x}_{\mathrm{i}}(\mathrm{k})\right|}{\left|\mathrm{x}_{0}(\mathrm{k})-\mathrm{x}_{\mathrm{i}}(\mathrm{k})\right|+\zeta \max _{\mathrm{i}} \max _{\mathrm{k}}\left|\mathrm{x}_{0}(\mathrm{k})-\mathrm{x}_{\mathrm{i}}(\mathrm{k})\right|}
$$

where:

$\zeta \quad$ the identifier; $\zeta \in(0,1)$. 
In order to define the degree of relation, the value of the weighting coefficient for the parameters $\mathrm{P}$, I and U should be determined, which should fulfil the following relationship:

$$
\sum_{\mathrm{k}=1}^{\mathrm{n}} \beta_{\mathrm{k}}=1
$$

The weighting factor is determined by all the team members involved in the analysis. The selection of experts has a fundamental impact on the obtained results, that is why they should be responsible people having vast knowledge about the system's functioning and risk management methods. The relationship between the potential causes and the optimal value of decision-making factors is expressed by the degree of grey relation (Pillay and Wang 2003):

$$
\Gamma\left(\mathrm{x}_{\mathrm{i}}, \mathrm{x}_{\mathrm{j}}\right)=\sum_{\mathrm{k}=1}^{\mathrm{n}} \beta_{\mathrm{k}} \gamma\left\{\mathrm{x}_{\mathrm{i}}(\mathrm{k}), \mathrm{x}_{\mathrm{j}}(\mathrm{k})\right\}
$$

The higher is the value obtained from the eq. (8), the smaller is the risk of the given event. Based on the degree of relationship, you can prioritize events and identify areas that need improvement what is consistent with WSP.

\section{Research Object and Results of Research}

\subsection{Determination of the Technical Condition of the Water Supply Network}

The analysis covers the district city located in south-eastern Poland. The city has about 37,000 inhabitants. The average $24-\mathrm{h}$ production of treated water is about $5600 \mathrm{~m}^{3} / \mathrm{d}$. The system of the water supply network is mixed, ring-branch (Fig. 2). On the basis of the book of failures made available by the water supply company, the value of the failure rate index of the water supply network in 2010-2015 was determined. The book of failures contained, among others, such information as: date and time of reporting, location of failure, date and time of beginning and end of failure removal, range of failure, causes and consequences of failure, diameter and material of pipe and materials used to remove failure. The average value of the failure rate index for the analysed water supply network in the analysed period was $\lambda=0,29$ failure $/(\mathrm{km}$. year), assumed $I=1$. The failure rate index in 2010-2015 determined on the basis of formula (2) is illustrated in Fig. 3 and its detailed analysis is included in the work (Szpak and Tchórzewska-Cieślak 2018). The calculation method of the yearly failure rate is presented in Table 2. The acquired knowledge about the failure rate has been linked with the time of interruption of water supply to consumers. This parameter has a significant impact on the sense of safety of water consumers and significantly affects the perception of the reliability and credibility of the water supply company. Table 3 presents the main causes of the failures of the water supply network in the analysed city in 2010-2015 and the average time of interruption of water supply to consumers. The proposed method applies to the water supply network. The analysis of other subsystems included in the WSS requires the use of the matrices presented in, for example (Rak and Pietrucha-Urbanik 2008).

Such a significant distribution of the failure rate index for the household connections is caused by a decrease in the number of household connections failures. This is probably the result of the operating strategy of the water supply company. The water supply network of the analyzed city is currently made of plastic (84\%), i.e. PE and PVC. Pipes made of gray cast iron 


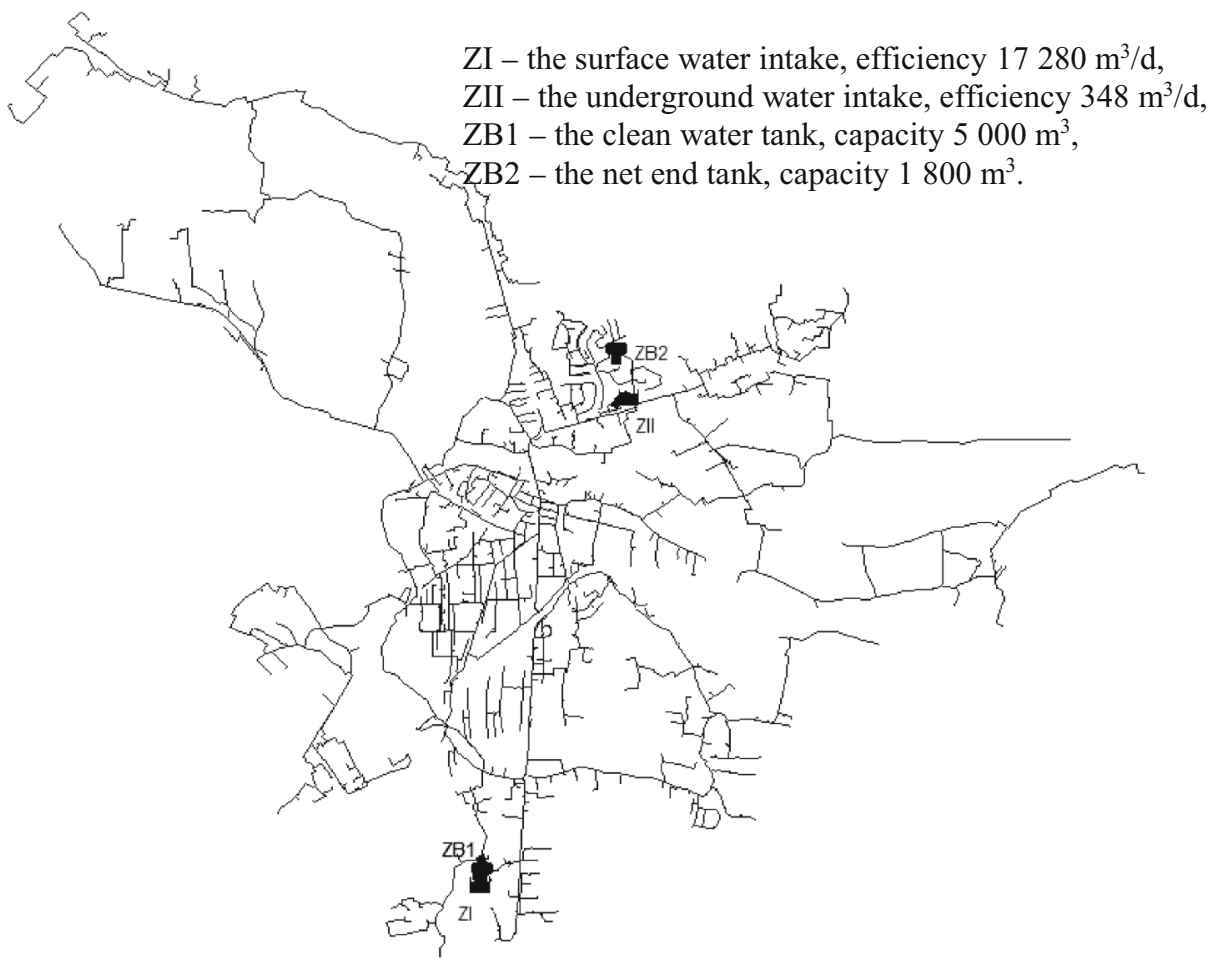

Fig. 2 Scheme of the water supply network

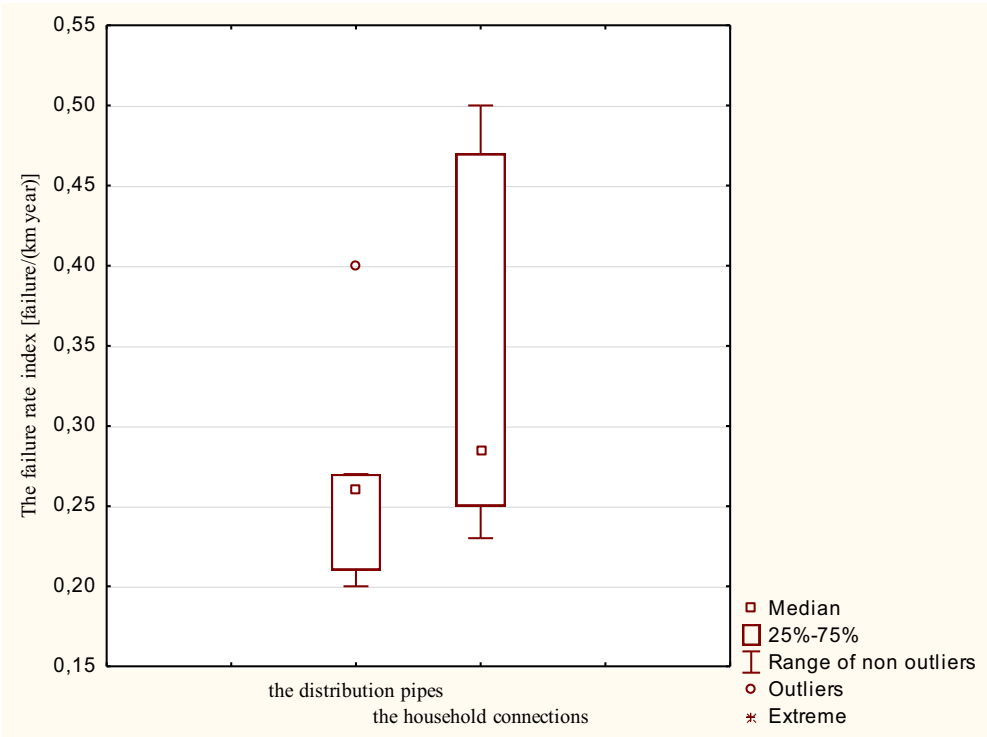

Fig. 3 The failure rate index for the distribution pipes and the household connections in 2010-2015 


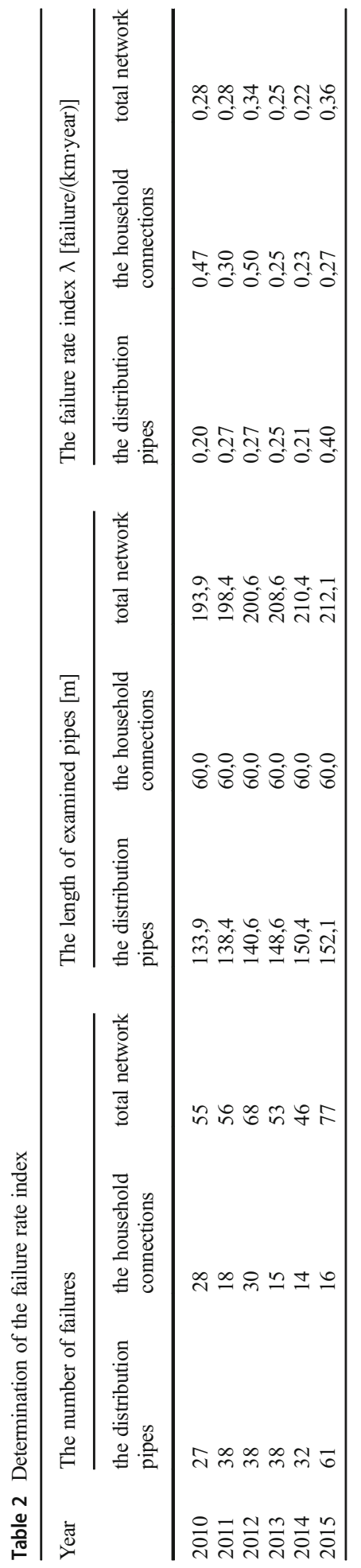


Table 3 Causes of the water supply network failures in 2010-2015

\begin{tabular}{lllll}
\hline Lp. Defect & No.of failures & $\begin{array}{l}\text { Percentage } \\
\text { share [\%] }\end{array}$ & $\begin{array}{l}\text { Average time of } \\
\text { interruption of } \\
\text { water supply [h] }\end{array}$ \\
\hline $1 \quad$ & & & $26,48(P=2)$ & $4,00(\mathrm{U}=2)$ \\
2 & Leak on the pipes connection & 94 & $24,79(P=1)$ & $1,62(\mathrm{U}=1)$ \\
& Damage to the fittings (fire hydrant, & 88 & & \\
$\quad \quad$ gate valve, air vent, dehydration, & & & $4,75(\mathrm{U}=2)$ \\
3 & $\quad$ water meter, pressure reducer) & 81 & $22,82(\mathrm{P}=1)$ & $5,26(\mathrm{U}=2)$ \\
4 & Corrosion of pipes & 57 & $16,05(\mathrm{P}=1)$ & $5,71(\mathrm{U}=2)$ \\
5 & Crack pipes & 12 & $3,38(\mathrm{P}=1)$ & $5,50(\mathrm{U}=2)$ \\
6 & Leak on the band & 11 & $1,97(\mathrm{P}=1)$ & $3,43(\mathrm{U}=2)$ \\
7 & The tee breaks & 7 & $0,85(\mathrm{P}=1)$ & $1,00(\mathrm{U}=1)$ \\
8 & Mechanical damage of pipes & 3 & $0,56(\mathrm{P}=1)$ & $1,25(\mathrm{U}=1)$ \\
9 & Mechanical damage of the fittings & 2 & $100(\mathrm{P}=1)$ & \\
\hline
\end{tabular}

and steel are gradually replaced (corrosion was the main reason household connections failures in the analyzed time). They are replaced with pipes made of PE. Changes in the material structure of the analyzed water supply network coincide with the global trend of using thermoplastics as a material for the construction of water supply networks, because they are characterized by significantly lower failure rates for steel and gray cast iron.

The condition of the water supply network was initially assessed based on the failure rate index. Because there are no applicable legal regulations regarding the admissible values of the failure rate index, the obtained results were referred to limit values of the failure rate index for particular types of pipes, given, among others in the work (Kwietniewski and Rak 2010): the distribution pipes: $\lambda_{R}=0,50$ failure/(km·year), the household connections: $\lambda_{\mathrm{PD}}=1,00$ failure/(km·year). As the received failure rate values are lower than the limit values, it was found that the water supply network of the analysed city is characterized by a good technical condition.

Lack of division into the distribution network and household connections (Table 3) results from the assumptions of the method, which focuses on the causes of the water supply network failures, taking into account the probability of a given type of failure and the consequences associated with it determined by the time of lack of water supply. The classification of pipes is in this case is not necessary. The Pareto-Lorenz diagram was drawn up (Hart and Hart 1989) based on Table 3. The method uses the assumption that a small number of causes is the reason for the majority of undesirable events. It allows to rank the causes of undesirable events in terms of frequency of occurrence (by constructing an appropriate graph), indicating the areas that need a corrective action. The Pareto-Lorenz diagram illustrating the causes of failures of the water supply network of the analysed city was presented in Fig. 4.

It was found that four causes of failures of the water supply network: leakage at the connection of pipes, damage to the fittings, corrosion of pipes and breakage of pipes account for $90.14 \%$ of all the failures. Therefore, in order to increase the reliability of the water supply network, measures should be taken to reduce the failures caused by the above-mentioned causes. The other five causes are responsible for only $9.86 \%$ of the water supply failures. However, the safety analysis should include not only the frequency of undesirable events, but also their consequences which was taken into account by introducing to the analysis a parameter related to the time of water supply interruption. Short-term interruptions in water 


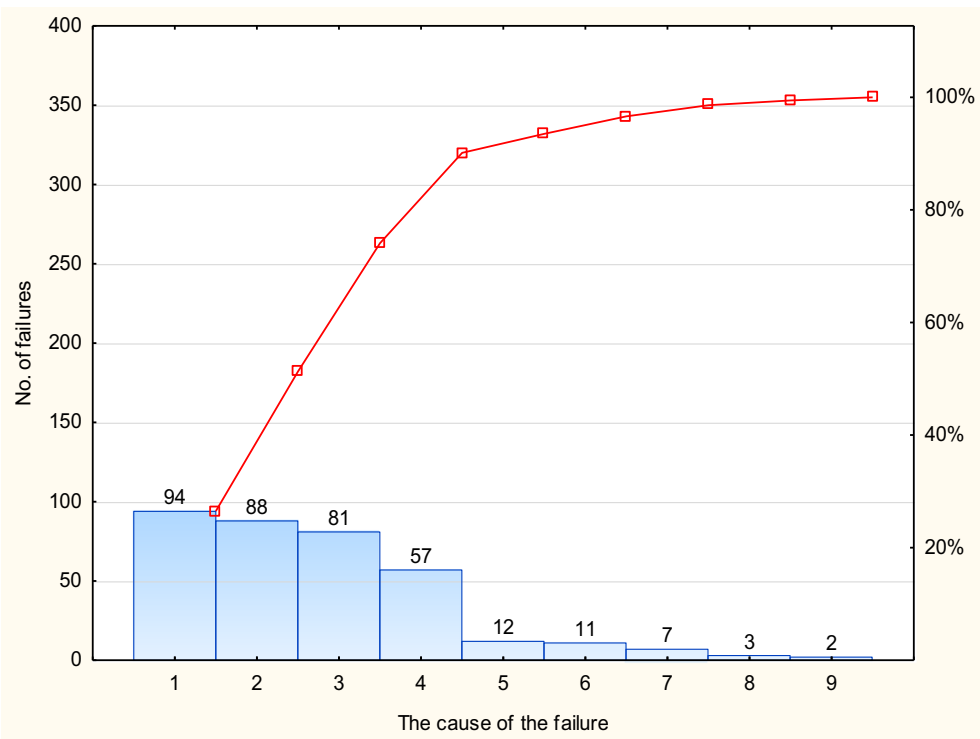

Fig. 4 Pareto-Lorenzo diagram illustrating the causes of failures of the water supply network

supply should be considered as a reliability state which does not affect the safety of water consumers (they often do not realize that a failure took place).

\subsection{Prioritization of Undesirable Events}

Based on the formula (3), the process of sharpening all the linguistic variables (in accordance with Fig. 1) was carried out:

- low

$$
\mathrm{K}(\mathrm{x})=\frac{\left(\mathrm{b}_{0}-\mathrm{c}\right)+\left(\mathrm{b}_{1}-\mathrm{c}\right)}{\left[\left(\mathrm{b}_{0}-\mathrm{c}\right)+\left(\mathrm{b}_{1}-\mathrm{c}\right)\right]-\left[\left(\mathrm{a}_{0}-\mathrm{d}\right)+\left(\mathrm{a}_{1}-\mathrm{d}\right)\right]}=\frac{(2-0)+(1-0)}{[(2-0)+(1-0)]-[(0-3)+(0-3)]}=0,333
$$

- $\quad$ medium

$$
\mathrm{K}(\mathrm{x})=\frac{\left(\mathrm{b}_{0}-\mathrm{c}\right)+\left(\mathrm{b}_{1}-\mathrm{c}\right)}{\left[\left(\mathrm{b}_{0}-\mathrm{c}\right)+\left(\mathrm{b}_{1}-\mathrm{c}\right)\right]-\left[\left(\mathrm{a}_{0}-\mathrm{d}\right)+\left(\mathrm{a}_{1}-\mathrm{d}\right)\right]}=\frac{(3-0)+(2-0)}{[(3-0)+(2-0)]-[(1-3)+(2-3)]}=0,625
$$

- $\quad$ high

$$
\mathrm{K}(\mathrm{x})=\frac{\left(\mathrm{b}_{0}-\mathrm{c}\right)+\left(\mathrm{b}_{1}-\mathrm{c}\right)}{\left[\left(\mathrm{b}_{0}-\mathrm{c}\right)+\left(\mathrm{b}_{1}-\mathrm{c}\right)\right]-\left[\left(\mathrm{a}_{0}-\mathrm{d}\right)+\left(\mathrm{a}_{1}-\mathrm{d}\right)\right]}=\frac{(3-0)+(3-0)}{[(3-0)+(3-0)]-[(2-3)+(3-3)]}=0,857 .
$$

The comparative series were developed on the basis of the linguistic variables assigned to the individual parameters describing each undesirable event, according to the relation (4), in the form of a matrix. The standard series was presented in the form of another matrix. The lowest 
level that each of the input parameters can achieve is "low", for which the value $\mathrm{K}(\mathrm{x})=0.333$. Then, according to the relationship (5), the difference between the comparison series and the standard series was determined.

$$
\begin{aligned}
& \mathrm{x}_{\mathrm{i}}=\left[\begin{array}{ccc}
\text { medium } & \text { low } & \text { medium } \\
\text { low } & \text { low } & \text { low } \\
\text { low } & \text { low } & \text { medium } \\
\text { low } & \text { low } & \text { medium } \\
\text { low } & \text { low } & \text { medium } \\
\text { low } & \text { low } & \text { medium } \\
\text { low } & \text { low } & \text { medium } \\
\text { low } & \text { low } & \text { low } \\
\text { low } & \text { low } & \text { low }
\end{array}\right]=\left[\begin{array}{ccc}
0,625 & 0,333 & 0,625 \\
0,333 & 0,333 & 0,333 \\
0,333 & 0,333 & 0,625 \\
0,333 & 0,333 & 0,625 \\
0,333 & 0,333 & 0,625 \\
0,333 & 0,333 & 0,625 \\
0,333 & 0,333 & 0,625 \\
0,333 & 0,333 & 0,333 \\
0,333 & 0,333 & 0,333
\end{array}\right] \\
& \mathrm{x}_{0}=\left[\begin{array}{lll}
\text { low } & \text { low } & \text { low } \\
\text { low } & \text { low } & \text { low } \\
\text { low } & \text { low } & \text { low } \\
\text { low } & \text { low } & \text { low } \\
\text { low } & \text { low } & \text { low } \\
\text { low } & \text { low } & \text { low } \\
\text { low } & \text { low } & \text { low } \\
\text { low } & \text { low } & \text { low } \\
\text { low } & \text { low } & \text { low }
\end{array}\right]=\left[\begin{array}{ccc}
0,333 & 0,333 & 0,333 \\
0,333 & 0,333 & 0,333 \\
0,333 & 0,333 & 0,333 \\
0,333 & 0,333 & 0,333 \\
0,333 & 0,333 & 0,333 \\
0,333 & 0,333 & 0,333 \\
0,333 & 0,333 & 0,333 \\
0,333 & 0,333 & 0,333 \\
0,333 & 0,333 & 0,333
\end{array}\right]
\end{aligned}
$$

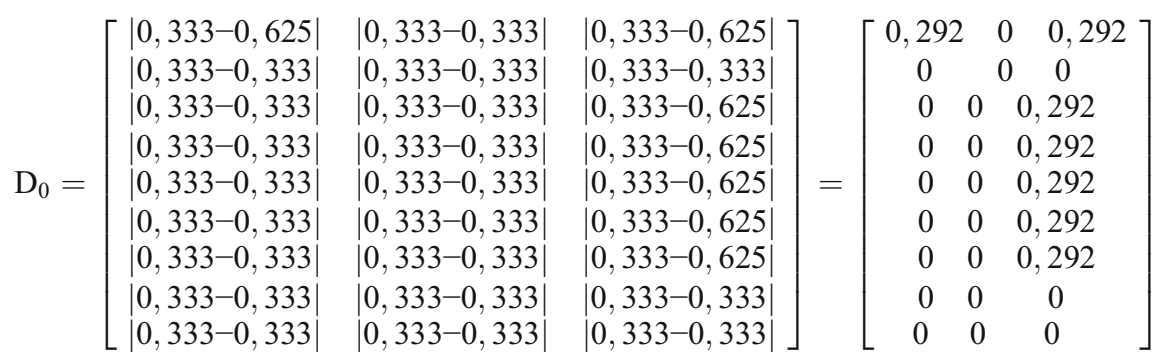

The next step involved the determination of the grey relation coefficient for each variable based on the dependence (6), which can be simplified to the form (Deng 1982):

$$
\gamma\left(\mathrm{x}_{0}(\mathrm{k}), \mathrm{x}_{\mathrm{i}}(\mathrm{k})\right)=\frac{\Delta_{\min }+\zeta \Delta_{\max }}{\Delta_{0 \mathrm{j}}(\mathrm{k})+\zeta \Delta_{\max }}
$$

where:

$$
\begin{array}{ll}
\Delta_{\min } & 0, \\
\Delta_{\max } & 0,292, \\
\zeta & 0,5 .
\end{array}
$$

The results of calculations for the analysed undesirable events are presented in Table 3. Next, the calculation example for the event marked 1 in Table 2 was presented:

$$
\gamma_{P}=\frac{0+0,5 \cdot 0,292}{0,292+0,5 \cdot 0,292}=0,333, \gamma_{I}=\frac{0+0,5 \cdot 0,292}{0+0,5 \cdot 0,292}=0,500, \gamma_{U}=\frac{0+0,5 \cdot 0,292}{0,292+0,5 \cdot 0,292}=0,333 \text {, }
$$


The purpose of the analysis is to identify areas particularly vulnerable to threats by assigning appropriate weights to the input parameters. According to the authors of the work, the greatest impact on the value of safety has the magnitude of the consequences of the undesirable event, in this case understood as the time of withholding the delivery of water to consumers. The following values of the weighing coefficient were determined for the input parameters:

- $\quad$ parameter $\mathrm{P}$ - weight 0.25 ,

- parameter I - weight 0.25 ,

- parameter U - weight 0.5 .

For the event marked 1 in Table 2 a degree of grey relation designated in accordance with relation (9) is:

$$
\Gamma\left(x_{i}, x_{j}\right)=0,25 \cdot 0,333+0,25 \cdot 0,500+0,5 \cdot 0,333=0,375 .
$$

The lower the value of the relationship degree, the greater threat to the safety of water supply to consumers. Based on Table 4, it was found that the greatest threat to the safety of water supply to consumers using the WSS covered by the analysis are failures of the water supply network related to leakage at the connection of pipes. These were mainly leaks in the muffs in flare connections of the pipes made of grey cast iron.

\section{Conclusions}

The discussed research problem was related to the development of the risk analysis and assessment methodology, which can be used for the needs of the WSP. The developed method applies to the water supply network, that is the most emergency subsystem included in the WSS. It takes into account the key parameters from the point of view of consumers: the failure rate of pipes, the percentage share of a given type of failure and the time of withholding the water supply. The determination of the value of $\Gamma$ enables both the prioritization of threats and the comparison of various WSS between each other.

Based on the conducted analysis, it was found that the greatest threat to the safety of water supply to consumers is related to leakage at the connection of pipes. For this reason, the water supply company should adopt a strategy for network renewal based primarily on the

Table 4 Prioritization of undesirable events

\begin{tabular}{lllllllll}
\hline $\begin{array}{l}\text { No. } \\
\text { share (P) }\end{array}$ & $\begin{array}{l}\text { Percentage } \\
\text { shate }\end{array}$ & Failure rate (I) & $\gamma_{\mathrm{I}}$ & $\begin{array}{l}\text { Suspension of } \\
\text { water supply (U) }\end{array}$ & $\gamma_{\mathrm{U}}$ & $\begin{array}{l}\Gamma \text { degree } \\
\text { of relation }\end{array}$ & Ranking \\
\hline 1 & medium & 0,333 & low & 0,500 & medium & 0,333 & 0,375 & 1 \\
2 & low & 0,500 & low & 0,500 & low & 0,500 & 0,500 & 3 \\
3 & low & 0,500 & low & 0,500 & medium & 0,333 & 0,417 & 2 \\
4 & low & 0,500 & low & 0,500 & medium & 0,333 & 0,417 & 2 \\
5 & low & 0,500 & low & 0,500 & medium & 0,333 & 0,417 & 2 \\
6 & low & 0,500 & low & 0,500 & medium & 0,333 & 0,417 & 2 \\
7 & low & 0,500 & low & 0,500 & medium & 0,333 & 0,417 & 2 \\
8 & low & 0,500 & low & 0,500 & low & 0,500 & 0,500 & 3 \\
9 & low & 0,500 & low & 0,500 & low & 0,500 & 0,500 & 3 \\
\hline
\end{tabular}


replacement of the oldest grey iron pipes for plastics. For this purpose, both excavation methods and trenchless methods (e.g. relining) can be used depending on economic and technical conditions. On the other hand, damage to the fittings, mechanical damage to the fittings and thawing of the pipes, in terms of the prioritization, are a relatively minor threat to the safety of water supply, mainly due to the short time when the water supply is stopped.

The value of $\Gamma$ is not a direct equivalent of the risk, but rather an indicator on which value you can prioritize undesirable events and thus indicate the areas requiring corrective action as the first. Undoubtedly, this is a very valuable information for the WSS operator. The method in question can be successfully used for the development of WSP. Based on its results, it is possible to achieve the main effects of the WSP, that is detailed, based on the specific numerical values, identification of undesirable events, development, implementation and continuous implementation of the improvement/modernization plan (based on the results of the analysis), defining monitoring of safety measures, preparation of management procedures and development of the support programs.

The limitations of the developed method stem from the fact that it focuses only on the amount of water supplied to consumers, omitting its quality. However, the possibility of secondary water pollution in the water supply network is also a current problem, especially due to the constantly decreasing water consumption in small cities, which is related to the rationalization of water consumption and the outflow of residents to large cities.

\section{Compliance with Ethical Standards}

\section{Conflict of Interest None.}

Open Access This article is distributed under the terms of the Creative Commons Attribution 4.0 International License (http://creativecommons.org/licenses/by/4.0/), which permits unrestricted use, distribution, and reproduction in any medium, provided you give appropriate credit to the original author(s) and the source, provide a link to the Creative Commons license, and indicate if changes were made.

\section{References}

Boryczko K, Tchórzewska-Cieślak B (2013) Analysis and assessment of the risk of lack of water supply using the EPANET program. In: Pawlowski A, Dudzinska MR, Pawlowski L (eds) Environmental engineering IV. Taylor \& Francis Group, London, pp 63-68

Byleveld PM, Deere D, Davison A (2008) Water safety plans: planning for adverse events and communicating with consumers. J Water Health 6:1):1-1):9

Chang CL, Wei CC, Lee YH (1999) Failure mode and effects analysis using fuzzy method and grey theory. Kybernetes 28(9):1072-1080

Chen CB, Klien CM (1997) A simple approach to ranking a group of aggregated fuzzy utilities. IEEE Trans Syst Man Cybern Part B: Cybern 27(1):26-35

Deng JL (1982) Control problems of Grey systems. Syst Control Lett 1(5):288-294

Deng JL (1989) Introduction to Grey system theory. J Grey Syst 1:1-24

Dodds L, King W, Allen AC et al (2004) Trihalomethanes in public water supplies and risk of stillbirth. Epidemiology 15(2):179-186

Foster JA, McDonald AT (2000) Assessing pollution risks to water supply intakes using geographical information systems (GIS). Environ Model Softw 15(3):225-234

Gunnarsdottir MJ, Gardarsson SM, Elliott M et al (2012) Benefits of water safety plans: microbiology, compliance, and public health. Environ Sci Technol 46(14):7782-7789

Hart KM, Hart RF (1989) Quantitative methods for quality improvement. ASQC Quality Press, Milwaukee

Kaplan S, Garrick BJ (1981) On the quantitative definition of risk. Risk Anal 1:11-27 
Kistemann T, Herbst S, Dangendorf F et al (2001) GIS-based analysis of drinking-water supply structures: a module for microbial risk assessment. Int J Hyg Environ Health 203(4):301-310

Kwietniewski M, Rak J (2010) Niezawodność infrastruktury wodociągowej i kanalizacyjnej w Polsce. Komitet Inżynierii Lądowej i Wodnej PAN, Warszawa

Maelzer HJ, Staben N, Hein A et al (2010) Identification, assessment, and control of hazards in water supply: experiences from water safety plan implementations in Germany. Water Sci Technol 61(5):1307-1315

Perrier E, Kot M, Castleden H et al (2014) Drinking water safety plans: barriers and bridges for small systems in Alberta, Canada. Water Policy 16(6):1140-1154

Piegdoń I, Tchórzewska-Cieślak B, Szpak D (2017) The use of geographical information system in the analysis of risk of failure of water supply network. In: Pawłowska A, Pawłowski L (eds) Environmental engineering V. Taylor \& Francis Group, London, pp 7-14

Pietrucha-Urbanik K, Studzinski A (2017) Case study of failure simulation of pipelines conducted in chosen water supply system. Eksploatacja i niezawodnosc - Maintenance and Reliability 19(3):317-323

Pillay A, Wang J (2003) Modified failure mode and effects analysis using approximate reasoning. Reliab Eng Syst Saf 79:69-85

Rak JR, Pietrucha-Urbanik K (2008) Risk in drinking water quality control. Przem Chem 87(5):554-556

Smeets PWMH, Rietveld LC, van Dijk JC et al (2010) Practical applications of quantitative microbial risk assessment (QMRA) for water safety plans. Water Sci Technol 61(6):1561-1568

Szpak D, Tchórzewska-Cieślak B (2018) Modelling of failure rate of water supply network using the Bayes theorem. E3S Web of Conf 44:00175

Tchorzewska-Cieslak B, Boryczko K, Eid M (2011) Failure scenarios in water supply system by means of fault tree analysis. Adv Saf Reliab Risk Manag:2492-2499

World Health Organization (2009) Water safety plan manual: step-by-step risk management for drinking-water suppliers. Geneva

Yin M-S (2013) Fifteen years of grey system theory research: a historical review and bibliometric analysis. Expert Syst Appl 40(7):2767-2775

Publisher's Note Springer Nature remains neutral with regard to jurisdictional claims in published maps and institutional affiliations. 